\title{
Three-Dimensional Finite Element Analysis and Characterization of Quasi-Surface Acoustic Wave Resonators
}

\author{
Wen Chen ${ }^{1}$, Linwei Zhang ${ }^{2}$, Shangshu Yang ${ }^{1}$, Wenhan Jia ${ }^{1}$, Songsong Zhang ${ }^{2}$, Yuandong Gu ${ }^{2}$, Liang Lou ${ }^{2, *}$ \\ and Guoqiang $\mathrm{Wu}{ }^{1, *(\mathbb{D})}$ \\ 1 Institute of Technological Sciences, Wuhan University, Wuhan 430072, China; wenwhu@whu.edu.cn (W.C.); \\ ssyang@whu.edu.cn (S.Y.); wh_j2019@whu.edu.cn (W.J.) \\ 2 Shanghai Industrial Technology Research Institute, Shanghai 201899, China; \\ Ethan.Zhang@sitrigroup.com (L.Z.); Songsong.Zhang@sitrigroup.com (S.Z.); Alex.Gu@sitrigroup.com (Y.G.) \\ * Correspondence: liang.lou@sitrigroup.com(L.L.); wuguoqiang@whu.edu.cn(G.W.)
}

check for updates

Citation: Chen, W.; Zhang, L.; Yang, S.; Jia, W.; Zhang, S.; Gu, Y.; Lou, L.; $\mathrm{Wu}, \mathrm{G}$. Three-Dimensional Finite Element Analysis and Characterization of Quasi-Surface Acoustic Wave Resonators. Micromachines 2021, 12, 1118. https: / /doi.org/10.3390/ mi12091118

Academic Editor: Giancarlo C. Righini and Joshua En-yuan Lee

Received: 19 July 2021

Accepted: 9 September 2021

Published: 17 September 2021

Publisher's Note: MDPI stays neutral with regard to jurisdictional claims in published maps and institutional affiliations.

Copyright: (c) 2021 by the authors. Licensee MDPI, Basel, Switzerland. This article is an open access article distributed under the terms and conditions of the Creative Commons Attribution (CC BY) license (https:/ / creativecommons.org/licenses/by/ $4.0 /)$.

\begin{abstract}
In this work, three-dimensional finite element analysis (3D FEA) of quasi-surface acoustic wave (QSAW) resonators with high accuracy is reported. The QSAW resonators consist of simple molybdenum (Mo) interdigitated transducers (IDT) on solidly mounted stacked layers of AlN/Mo/Si. Different to the SAW resonators operating in the piezoelectric substrates, the reported resonators are operating in the QSAW mode, since the IDT-excited Rayleigh waves not only propagate in the thin piezoelectric layer of AlN, but also penetrate the Si substrate. Compared with the commonly used two-dimensional (2D) FEA approach, the 3D FEA method reported in this work shows high accuracy, in terms of the resonant frequency, temperature coefficient of frequency $(T C F)$, effective coupling coefficient $\left(k_{e f f}^{2}\right)$ and frequency response. The fabricated QSAW resonator has demonstrated a $k_{e f f}^{2}$ of $0.291 \%$, series resonant frequency of $422.50 \mathrm{MHz}$, and $T C F$ of $-23.418 \mathrm{ppm} /{ }^{\circ} \mathrm{C}$ in the temperature range between $30^{\circ} \mathrm{C}$ and $150{ }^{\circ} \mathrm{C}$, for the design of wavelength at $10.4 \mu \mathrm{m}$. The measurement results agree well with the simulations. Moreover, the QSAW resonators are more mechanically robust than lamb wave devices and can be integrated with silicon-based film bulk acoustic resonator (FBAR) devices to offer multi-frequency function in a single chip.
\end{abstract}

Keywords: quasi-surface acoustic wave (QSAW) resonator; microelectromechnical systems (MEMS); finite element analysis; aluminum nitride

\section{Introduction}

Surface acoustic wave (SAW) devices are one of the most popular microelectromechnical systems (MEMS) devices at high frequency and super high frequency, which have been widely used in filters, actuators and sensors applications [1-4]. SAW devices are usually fabricated based on lithium niobate $\left(\mathrm{LiNbO}_{3}\right)$ piezoelectric substrate and have demonstrated excellent performance of high-quality factor $(Q)$ as well as large effective coupling coefficient [5-8]. However, $\mathrm{LiNbO}_{3}$ has high electrical impedance at high frequency, resulting in electrical matching challenge with the ultrasound system electronics. $\mathrm{LiNbO}_{3}$ suffers from lower phase velocity and poor complementary metal oxide semiconductor (CMOS) compatibility compared with state-of-art aluminum nitride (AIN)-based piezoelectric devices. AlN is a kind of promising piezoelectric material and shows high performance in MEMS piezoelectric devices due to its ultra-high acoustic velocity, high thermal conductivity and good CMOS compatibility [9]. Thus, AlN-based devices offer excellent performance and good manufacturability [10]. AlN is usually deposited as a piezoelectric thin film on a silicon substrate by physical vapor deposition (PVD). Different to the SAW resonator operating in the piezoelectric substrate, acoustic waves excited by interdigitated transducers (IDT) for AIN thin-film-based SAW devices not only propagate in the thin piezoelectric layer of AlN, but also penetrate the Si substrate. Thus, the AlN thin-film-based SAW resonator is more likely to be a kind of quasi-SAW (QSAW) device. 
In the early days, numerical calculation is the primary method to investigate SAW resonators. Theoretical studies have been conducted to calculate velocity, coupling coefficient, admittance response and other parameters of SAW transducers roughly [11-13]. With the development of computer simulation, finite element analysis (FEA) becomes an important and convenient approach for researchers to optimize designs for SAW devices. Twodimensional (2D) FEA is a typical method to investigate and design SAW transducers and resonators, which provides a simple and quick way for SAW device simulations [14-17]. 2D models can be used for quickly obtaining the design parameters, such as frequency, coupling coefficient and phase velocity. However, this method is not accurate, since 2D models miss many key parameters of the devices and the boundary conditions are quite different to the real scenarios. The results by numerical calculation and $2 \mathrm{D}$ simulation have difficulties in matching well with the measurement results sometimes. Therefore, both numerical calculation and 2D simulation have limitations in investigating SAW resonators. Simulations based on 3D models can acquire more accurate results, such as series resonance frequency $f_{s}$, parallel resonance frequency $f_{p}, Q, k_{e f f}^{2}$ and other parameters. Simulations based on 3D models are more complicated, but 3D models are closer to real devices than 2D models. Therefore, 3D FEA designs are more accurate and instructive.

In this work, 3D FEA of the solidly mounted stacked layers of AlN/molybdenum (Mo)/Si for QSAW resonators with grounded Mo electrodes are presented. The grounding of the bottom Mo electrode can improve the $k_{e f f}^{2}$ of QSAW resonator compared with conventional SAW resonator [18]. 3D FEA simulations are carried out to optimize designs. To verify the accuracy of the 3D FEA approach, key parameters for designing QSAW resonators such as frequency, admittance response, $k_{e f f}^{2}$ and temperature coefficient of frequency $(T C F)$ are investigated and discussed in both simulation and experiment.

\section{Device Design}

The QSAW resonators consist of Mo IDTs and reflectors laid on the solidly mounted stacked structure of AlN/Mo/Si layers, as shown in Figure 1. Both 2D and 3D FEA simulations are conducted in COMSOL Multiphysics (COMSOL Multiphysics 5.4, COMSOL $\mathrm{AB}$, Stockholm, Sweden), in order to compare their differences. The QSAW resonators are designed with four different wavelengths, $\lambda$, of $10.4 \mu \mathrm{m}, 10 \mu \mathrm{m}, 9.6 \mu \mathrm{m}$ and $9.2 \mu \mathrm{m}$. In this work, split IDT design, rather than typical IDT structure, is adopted to reduce the insertion loss and improve the frequency stability [19]. The split IDT is composed of a grating structure with interval of $\lambda / 8$ and a center-to-center distance of $\lambda / 4$. The aperture length is designed as $50 \lambda$. The IDT fingers number and reflector gratings number are 60 pairs and 80 pairs, respectively. The simulated displacement profiles of the $2 \mathrm{D}$ and 3D models are shown in Figure 1. In 2D simulations, periodic boundary conditions are applied on the left and right sides of the model, as shown in Figure 1c. For 3D simulations as shown in Figure 1b, the model is anti-symmetric in the center plane (the leftmost plane in Figure 1b). The displacement profile in the 3D FEA model is presented in Figure 1d.

In the simulations, space between IDT fingers area and reflector gratings area is varied to optimize designs of the QSAW resonators. The impedance responses of QSAW resonators with $\lambda$ of $10.4 \mu \mathrm{m}$ for different spaces of $2 \lambda / 32,3 \lambda / 32$ and $4 \lambda / 32$ are obtained in 3D FEA simulations. As shown in Figure 2, the impedance response of resonator with space of $2 \lambda / 32$ is better than that of other two cases. Moreover, spurious mode amplitude at about $426 \mathrm{MHz}$ is obviously smaller for the design with space of $2 \lambda / 32$. In other words, the signal response at series resonance frequency is heightened and undesired spurious mode is suppressed for optimized space. Smaller space between IDT fingers and reflector gratings will reflect more surface acoustic waves back to IDT fingers area, resulting in stronger frequency response at series resonance frequency and less spurious modes. However, the patterning of tiny space around hundreds of nanometers is extremely challenging in lithographic process due to the critical dimension limitations of the tool used. Therefore, the space is set as $2 \lambda / 32$ in this work. Table 1 lists the detailed parameters of the QSAW 
resonators. In simulations, the material parameters of all layers included in models are presented in Table 2, which are adopted from [20,21].

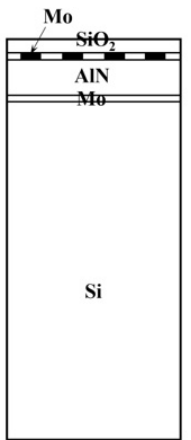

(a)

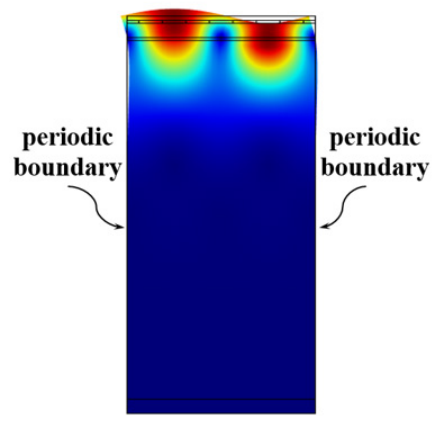

(c)

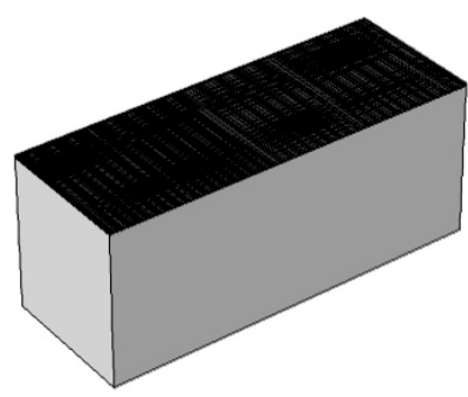

(b)

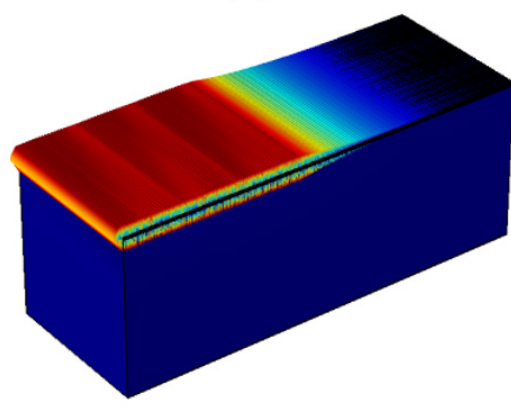

(d)

Figure 1. Illustration of 2D and 3D FEA models and simulated displacement profiles of the QSAW resonators: (a) Simplified 2D FEA model structure. (b) 3D FEA model structure. (c) 2D FEA displacement profile. (d) 3D FEA displacement profile.

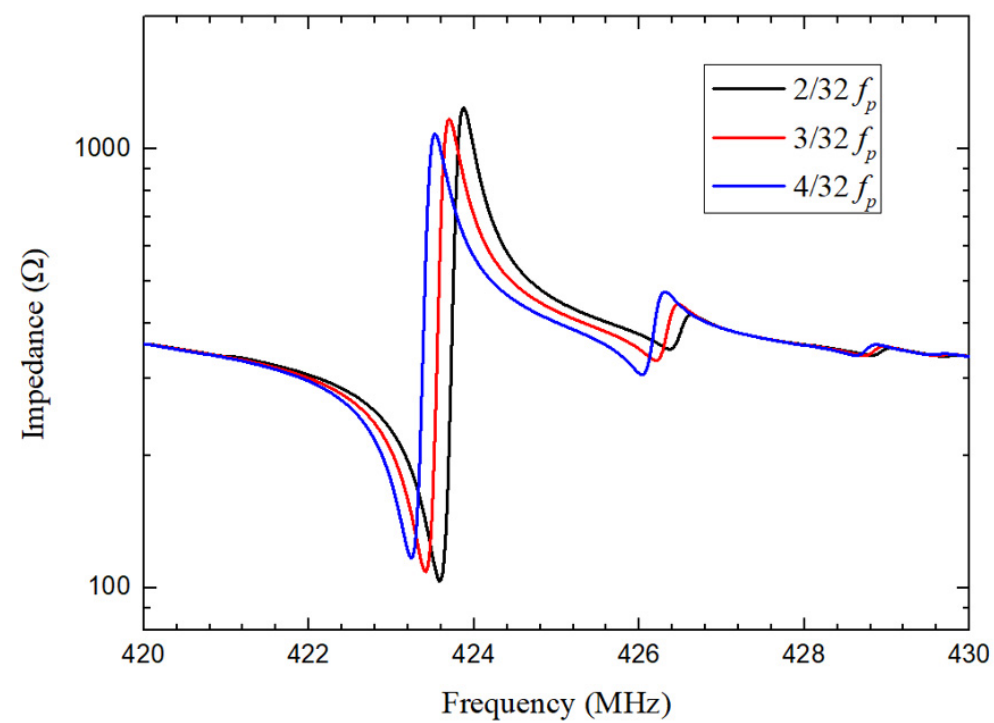

Figure 2. Simulated impedance curves of QSAW resonator with $\lambda$ of $10.4 \mu \mathrm{m}$ for different spaces of $2 \lambda / 32,3 \lambda / 32$ and $4 \lambda / 32$. 
Table 1. Design parameters of QSAW resonators.

\begin{tabular}{lc}
\hline IDT fingers number & 60 pairs \\
Reflector gratings number & 80 pairs \\
& $10.4 \mu \mathrm{m}$ \\
Wavelength $(\lambda)$ & $10 \mu \mathrm{m}$ \\
& $9.6 \mu \mathrm{m}$ \\
Space & $9.2 \mu \mathrm{m}$ \\
Aperture length & $2 \lambda / 32$ \\
\hline
\end{tabular}

Table 2. Material parameters of all layers used in the simulations.

\begin{tabular}{cccccc}
\hline & & AlN & Si & SiO $_{2}$ & Mo \\
\hline Elastic constants, $c_{i j}(\mathrm{GPa})$ & $c_{11}$ & 410.06 & 165.6 & 70 & 329 \\
& $c_{12}$ & 100.69 & 63.9 & & \\
& $c_{13}$ & 83.82 & & & \\
& $c_{33}$ & 386.24 & & & \\
& $c_{44}$ & 100.58 & 79.5 & & \\
& $c_{66}$ & 154.70 & & & \\
\hline Relative permittivity, $\varepsilon_{i j}$ & $\varepsilon_{31}$ & 9 & & \multirow{2}{*}{4.2} & \\
& $\varepsilon_{33}$ & 11 & & 4.2 & \\
\hline Density, $\rho\left(\mathrm{kg} / \mathrm{m}^{3}\right)$ & & 3260 & 2329 & 2200 & 10,200 \\
\hline Piezoelectric stress constants, & $e_{15}$ & -0.48 & & & \\
$e_{i j}\left(\mathrm{C} / \mathrm{m}^{2}\right)$ & $e_{31}$ & -0.58 & & & \\
& $e_{33}$ & 1.55 & & & \\
\hline
\end{tabular}

\section{Device Fabrication}

Figure 3 illustrates the fabrication process of the QSAW resonators. The fabrication starts with a $500-\mu \mathrm{m}$-thick $\mathrm{Si}$ wafer as substrate. Next, a $0.2-\mu \mathrm{m}$-thick Mo thin film is deposited on the wafer as bottom electrode, and followed by $1-\mu \mathrm{m}$-thick c-axis oriented AlN piezoelectric thin film and another $0.2-\mu \mathrm{m}$-thick Mo thin film depositions using sputtering. Then, the top Mo layer is patterned to define IDT fingers and reflector gratings. After that, a $0.5-\mu \mathrm{m}$-thick oxide is deposited using plasma enhanced chemical vapor deposition (PECVD) on the top Mo layer to prevent the top electrode from being oxidized. Electric contact vias are defined and patterned to access the top and bottom Mo electrodes, respectively. Finally, a 1- $\mu \mathrm{m}$-thick aluminum layer is deposited and patterned to form the bonding pads and connection lines.

The optical microscope images of a fabricated QSAW resonator are shown in Figure 4. The IDT fingers are located at the center area, and the reflector gratings are located at two flanks. The IDT fingers and reflector gratings are clearly visible as displayed in Figure $4 \mathrm{~b}$. The space between IDT fingers and reflector gratings is defined as $2 \lambda / 32$. 


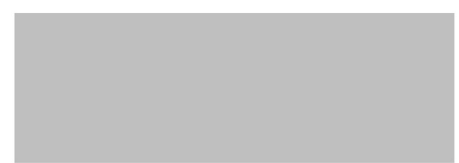

(a)

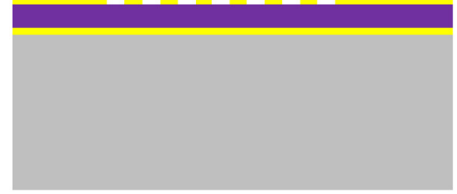

(c)

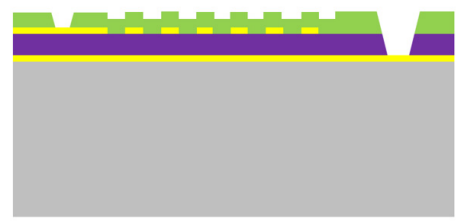

(e)

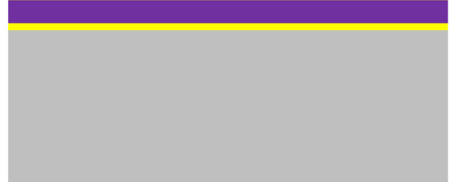

(b)

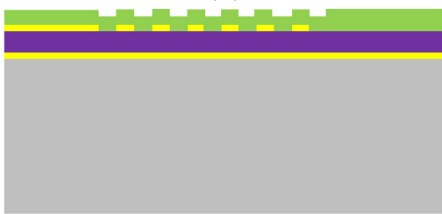

(d)

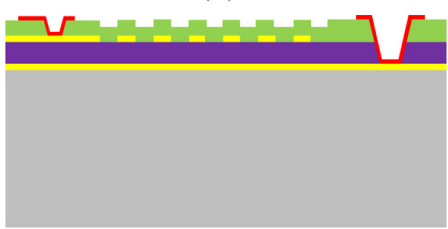

(f)

$\mathrm{Si} \quad \mathrm{SiO}_{2}$ Mo AlN $\mathrm{Al}$

Figure 3. Process flow of the QSAW resonators. (a) Starting with a Si wafer, (b) Mo/AlN/Mo layers deposition, (c) Top Mo layer patterning to define IDT fingers and reflector gratings, (d) Top oxide deposition, (e) Contact vias opening to access the top and bottom electrodes, (f) Al deposition and patterning to form the bonding pads and connection lines.

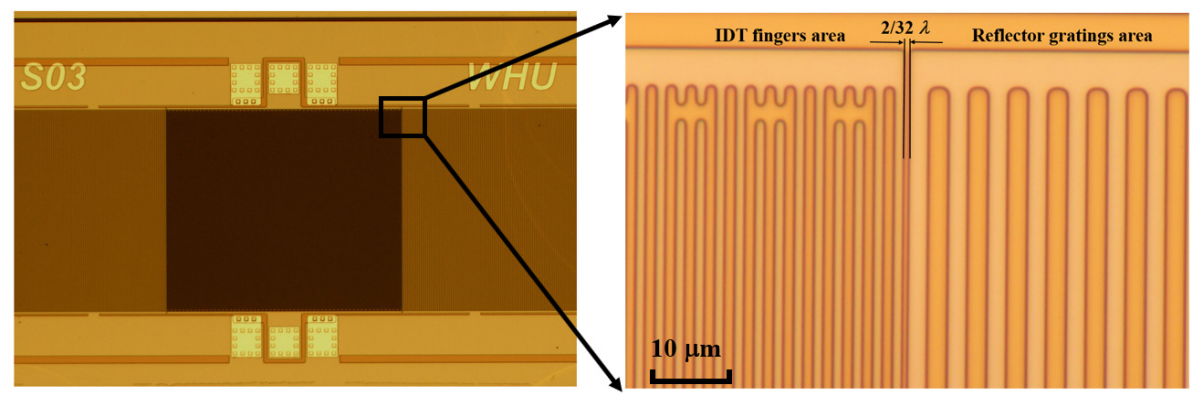

(a)

(b)

Figure 4. Optical microscope images of a fabricated QSAW resonator: (a) overall view of resonator, (b) zoom-in view of space between IDT fingers and reflector gratings.

\section{Results}

Scattering $(S)$ parameters of the fabricated QSAW resonators are characterized by a Keysight vector network analyzer in air with an open chamber probe station at room temperature. The devices are measured with ground-signal-ground (GSG) probes after conducting a standard short-open-load-through calibration using a standard calibration substrate. The measured S11 and S21 curves for fabricated resonator with $\lambda$ of $10.4 \mu \mathrm{m}$ in a wide frequency range from $380 \mathrm{MHz}$ to $480 \mathrm{MHz}$ are shown in Figure 5 . As displayed in Figure 5, the series resonance frequency $f_{s}$ and the parallel resonance frequency $f_{p}$ are $422.50 \mathrm{MHz}$ and $422.99 \mathrm{MHz}$, respectively. The insertion loss is $-16.54 \mathrm{~dB}$ and $Q$ is 1616 at its series resonance frequency. 


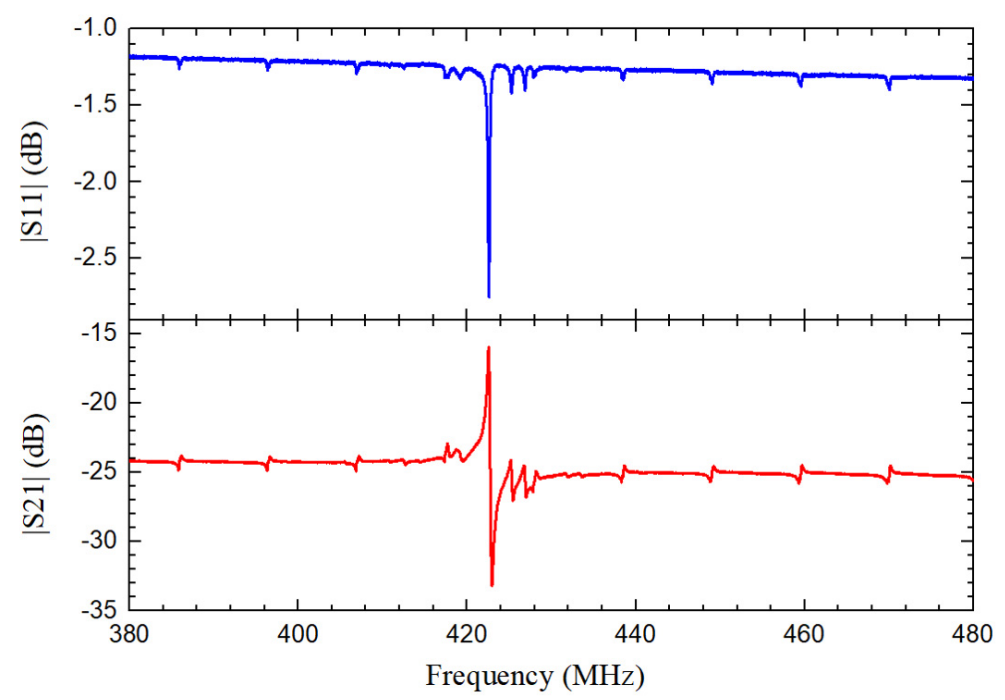

Figure 5. Measured S11 and S21 curves of the QSAW resonator with $\lambda$ of $10.4 \mu \mathrm{m}$ in a wide frequency range from $380 \mathrm{MHz}$ to $480 \mathrm{MHz}$.

$\lambda$ is set as $10.4 \mu \mathrm{m}, 10 \mu \mathrm{m}, 9.6 \mu \mathrm{m}$ and $9.2 \mu \mathrm{m}$ to verify the frequency accuracy of 3D FEA simulation. Comparison of the simulated and measured $f_{s}$ under different $\lambda$ is illustrated in Figure 6. It should be noted that the frequencies of fabricated resonators are very consistent with the 3D FEA simulated results. Although there is significant deviation between measured results and 2D FEA simulated results. This indicates that the 3D FEA simulations show higher accuracy in obtaining the simulated frequencies compared to the 2D FEA approach. The dimensions and configuration of 3D model are consistent with the practical scenario of the fabricated QSAW resonator. However, a simplified mode is used in 2D FEA approach and hence the setting of the boundary conditions is not consistent with the practical situation, resulting in large deviations between the simulation and measurement. Measured admittance response of the QSAW resonator with $\lambda$ of $10.4 \mu \mathrm{m}$ is also analyzed and compared with simulation result. Measured and simulated admittance responses of the above mentioned QSAW resonator in a frequency range from $400 \mathrm{MHz}$ to $450 \mathrm{MHz}$ are presented in Figure 7. The simulated frequency response is almost coincided with measured frequency response. However, simulated admittance response at series resonance frequency is slightly better than measurement result due to higher $Q$ used in the simulation. This is because some energy loss mechanisms such as the phonon-phonon interaction loss are not considered in simulations. There is a slight difference of series and parallel resonance frequencies between the simulated values and the measurement results, as displayed in Figure 7. The possible reason is that the material parameters in 3D FEA model are different to the real parameters of the materials used. 


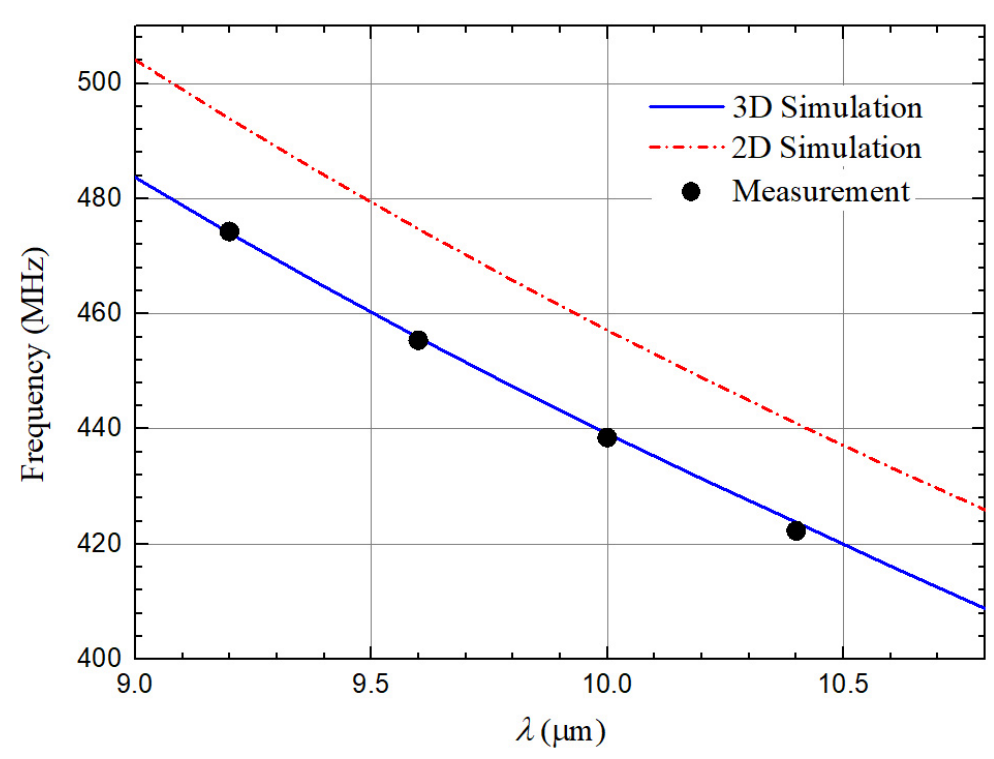

Figure 6. 2D, 3D FEA simulated and measured frequencies with different $\lambda$.

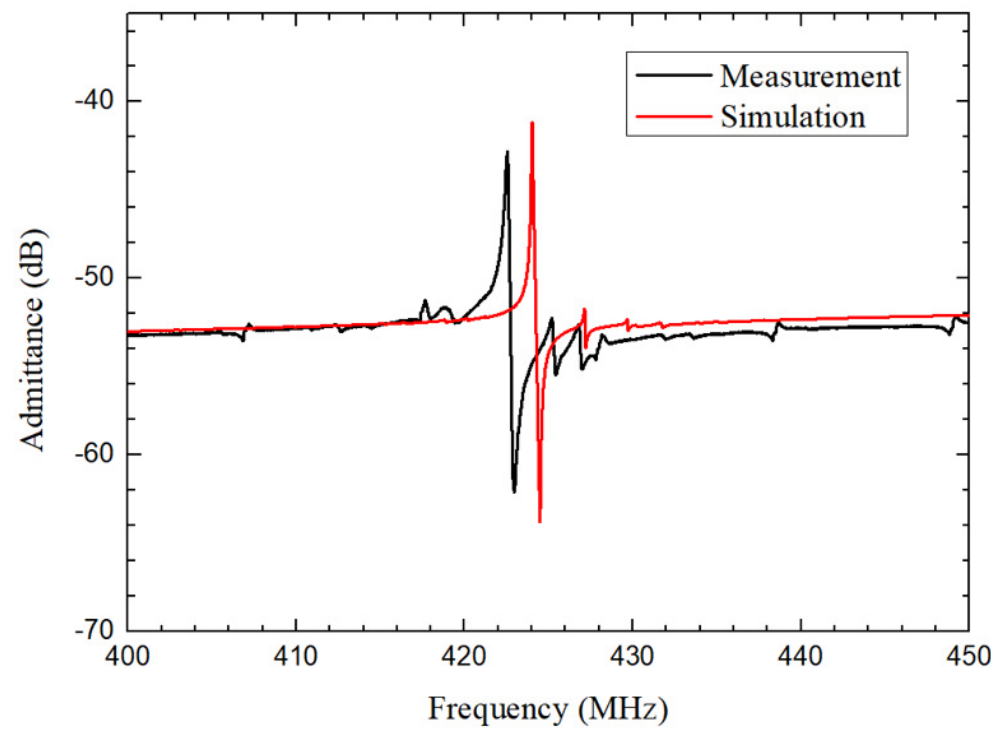

Figure 7. Measured and simulated admittance responses of the QSAW resonator with $\lambda$ of $10.4 \mu \mathrm{m}$ in a frequency range from $400 \mathrm{MHz}$ to $450 \mathrm{MHz}$.

$k_{e f f}^{2}$ of QSAW resonator is also investigated and compared in both simulation and experiment. $k_{\text {eff }}^{2}$ is defined as following [22]:

$$
k_{e f f}^{2}=\frac{\pi^{2}}{4} \frac{f_{s}}{f_{p}} \frac{f_{p}-f_{s}}{f_{p}},
$$

The simulated and measured $k_{e f f}^{2}$ of QSAW resonators with different $\lambda$ are displayed in Figure 8. The measured and simulated results are extremely close, which indicates the high accuracy of 3D simulation. 


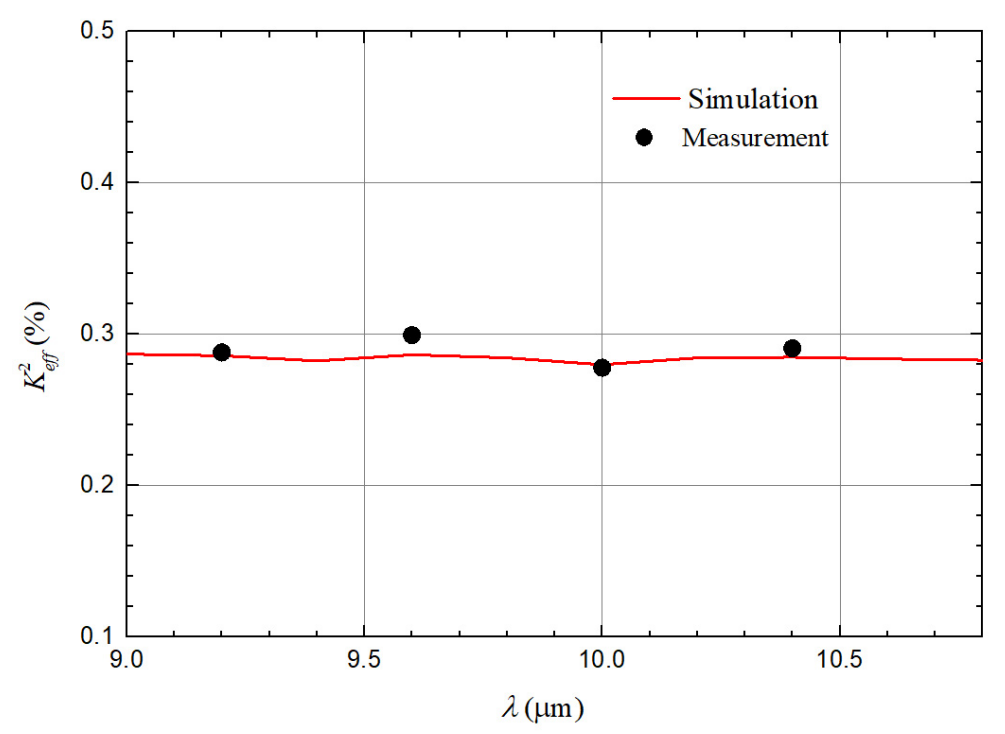

Figure 8. Measured and simulated $k_{e f f}^{2}$ of the QSAW resonator with different $\lambda$.

The TCFs of QSAW resonators with $\lambda$ of $10.4 \mu \mathrm{m}, 10 \mu \mathrm{m}, 9.6 \mu \mathrm{m}$ and $9.2 \mu \mathrm{m}$ are measured in a temperature range from $30{ }^{\circ} \mathrm{C}$ to $150{ }^{\circ} \mathrm{C}$. The TCF measurements are conducted in a cryogenic probe station. The simulated and measured TCFs of QSAW resonator with $\lambda$ of $10.4 \mu \mathrm{m}$ are presented in Figure 9. The simulated and measured TCFs are $-24.131 \mathrm{ppm} /{ }^{\circ} \mathrm{C}$ and $-23.418 \mathrm{ppm} /{ }^{\circ} \mathrm{C}$, respectively. It is noted there is a small difference between simulated and measured results, due to the imperfection of the material parameters and the process tolerances in the fabrication.

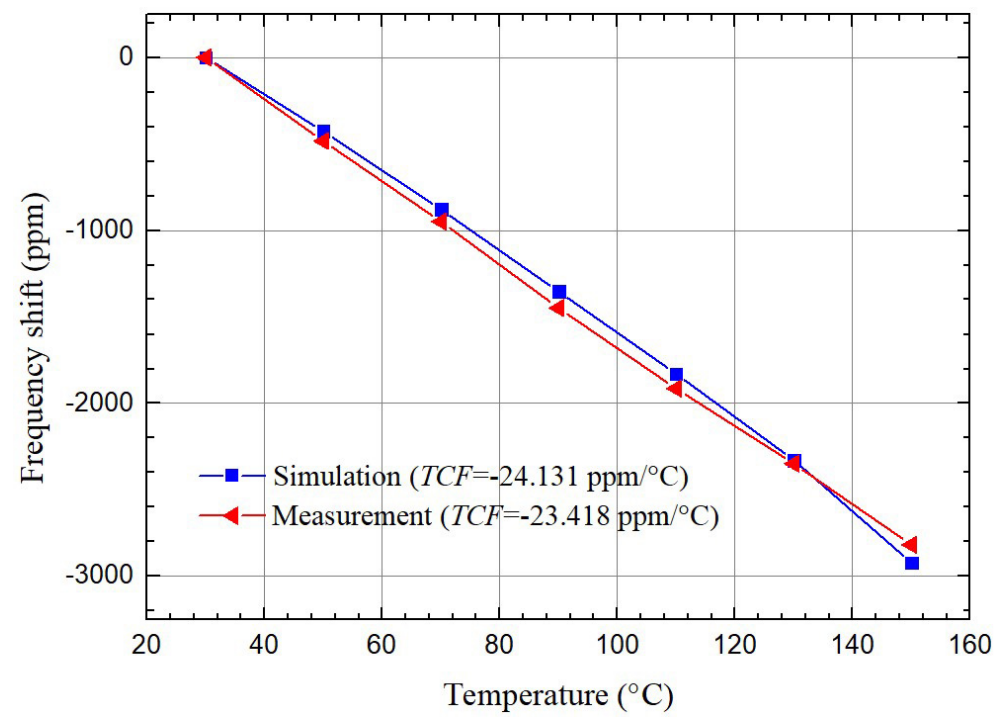

Figure 9. Measured and simulated TCFs of the QSAW resonator with $\lambda$ of $10.4 \mu \mathrm{m}$ in a temperature range from $30^{\circ} \mathrm{C}$ to $150{ }^{\circ} \mathrm{C}$.

The measured and 3D FEA simulated results with relative errors are presented in Table 3. The simulated frequencies for QSAW resonators are very close to measured results. The measured and 3D FEA simulated results of $k_{e f f}^{2}$ and TCF are close for QSAW resonators with $\lambda$ of $10.4 \mu \mathrm{m}, 10 \mu \mathrm{m}$ and $9.6 \mu \mathrm{m}$. However, there is a little deviation between simulated and measured results of TCF for QSAW resonator with $\lambda$ of $9.2 \mu \mathrm{m}$. As illustrated in the table, the negligible differences between simulation and measurement results indicate high accuracy of the 3D FEA simulations for the QSAW resonator. 
Table 3. Comparison of simulation and measurement results.

\begin{tabular}{|c|c|c|c|c|c|}
\hline \multicolumn{2}{|c|}{$\lambda(\mu \mathrm{m})$} & 10.4 & 10 & 9.6 & 9.2 \\
\hline \multirow{2}{*}{$\begin{array}{c}\text { Frequency } \\
(\mathrm{MHz})\end{array}$} & Simulation & 423.18 & 439.17 & 455.84 & 473.99 \\
\hline & Measurement & 422.50 & 438.68 & 455.39 & 474.27 \\
\hline \multicolumn{2}{|c|}{ Error } & $0.16 \%$ & $0.112 \%$ & $0.098 \%$ & $0.059 \%$ \\
\hline \multirow{2}{*}{$K_{e f f}^{2}$} & Simulation & $0.285 \%$ & $0.280 \%$ & $0.286 \%$ & $0.286 \%$ \\
\hline & Measurement & $0.291 \%$ & $0.278 \%$ & $0.299 \%$ & $0.288 \%$ \\
\hline \multicolumn{2}{|c|}{ Error } & $1.99 \%$ & $0.732 \%$ & $4.42 \%$ & $0.743 \%$ \\
\hline \multirow{2}{*}{$\begin{array}{c}\text { TCF } \\
\left(\mathrm{ppm} /{ }^{\circ} \mathrm{C}\right)\end{array}$} & Simulation & -24.131 & -24.616 & -25.088 & -25.094 \\
\hline & Measurement & -23.418 & -25.102 & -26.117 & -28.056 \\
\hline \multicolumn{2}{|c|}{ Error } & $2.69 \%$ & $1.97 \%$ & $4.10 \%$ & $11.804 \%$ \\
\hline
\end{tabular}

\section{Conclusions}

In this work, a 3D FEA approach for designing QSAW resonators with high accuracy is presented. To validate the accuracy of the 3D FEA method, the QSAW resonators with $\lambda$ of $10.4 \mu \mathrm{m}, 10 \mu \mathrm{m}, 9.6 \mu \mathrm{m}$ and $9.2 \mu \mathrm{m}$ are designed, fabricated and characterized. The reported QSAW resonator is composed of a solidly mounted stacked structure of AlN/Mo/Si layers with split Mo IDT fingers laid on the surface. The measured frequencies of QSAW resonators for different $\lambda$ are consistent with 3D simulation results and have significant deviations with 2D simulation results, indicating high accuracy of 3D FEA simulation. The admittance response, $k_{e f f}^{2}$ and TCF are also investigated and compared in both simulations and measurements. The measurement results are in good agreement with 3D FEA simulation values, which indicates high accuracy of 3D FEA simulation. Key parameters of QSAW or SAW resonators can be obtained accurately through simulations, which is crucial for designing QSAW or SAW resonators with high performance in practical applications.

Author Contributions: Conceptualization, G.W., Y.G. and L.L.; methodology, W.C., L.Z. and W.J.; simulation, S.Y. and W.C.; validation, G.W., L.L. and W.C.; fabrication, L.Z., S.Z. and Y.G.; writingoriginal draft preparation, W.C.; writing—review and editing, G.W., Y.G. and L.L.; project administration, G.W. All authors have read and agreed to the published version of the manuscript.

Funding: This work was supported in part by the National Natural Science Foundation of China under Grant 51905386 and in part by the Fundamental Research Funds for the Central Universities under Grant 2042021kf0191.

Conflicts of Interest: The authors declare no conflict of interest.

\section{Abbreviations}

$\begin{array}{ll}Q & \text { Qulity factor, } \\ k_{\text {eff }}^{2} & \text { Effective coupling coefficient, } \\ \lambda & \text { Wavelength, } \\ c & \text { Elastic constant, } \\ \varepsilon & \text { Relative permittivity, } \\ \rho & \text { Density, }\end{array}$




$$
\begin{array}{ll}
e & \text { Piezoelectric stress constant, } \\
f_{s} & \text { Series resonance frequency, } \\
f_{p} & \text { Parallel resonance frequency }
\end{array}
$$

\section{References}

1. Kobayashi, F.; Goka, S.; Wada, K.; Kakio, S. Electrical characteristics of SAW filters on $\mathrm{SiO}_{2} / \mathrm{Al} / \mathrm{LiNbO}_{3}$ structure for inverter multiplex transmission systems. IEEE Int. Ultrason. Symp. (IUS) 2017, 1-4.10.1109/ULTSYM.2017.8092321. [CrossRef]

2. Kajii, S.; Kong, D.; Nishio, K.; Kurosawa, M.K. Propulsion measurement of high frequency underwater SAW actuators. IEEE Int. Ultrason. Symp. (IUS) 2020, 1-4. [CrossRef]

3. Devkota, J.; Ohodnicki, P.R.; Greve, D.W. SAW sensors for chemical vapors and gases. Sensors 2017, 17, 801. [CrossRef]

4. Zhou, X.; Tan, Q.; Liang, X.; Lin, B.; Guo, T.; Gan, Y. Novel multilayer SAW temperature sensor for ultra-high temperature environments. Micromachines 2021, 12, 643. [CrossRef] [PubMed]

5. Tseng, W.K.; Lin, J.L.; Sung, W.C.; Chen, S.H.; Lee, G.B. Active micro-mixers using surface acoustic waves on Y-cut 128 LiNbO 3 . J. Micromech. Microeng. 2006, 16, 539. [CrossRef]

6. Feng, C.T.; Cheng, C.J.; Atashbar, M.Z. PMMA/64 YX-LiNbO 3 guided SH-SAW based immunosensing system. IEEE Sens. 2011, 308-311. [CrossRef]

7. Nakamura, H.; Nakanishi, H.; Tsurunari, T.; Matsunami, K.; Iwasaki, Y. 6E-1 A Small-Sized SAW Duplexer on a SiO 2 /IDT/LiNbO 3 Structure for Wideband CDMA Application. IEEE Ultrason. Symp. 2007, 488-491.10.1109/ULTSYM.2007.131. [CrossRef]

8. Hu, B.; Zhang, S.; Zhang, H.; Lv, W.; Zhang, C.; Lv, X.; San, H. Fabrications of L-band $\mathrm{LiNbO}_{3}$-based SAW resonators for aerospace applications. Micromachines 2019, 10, 349. [CrossRef]

9. Wu, G.; Xu, J.; Ng, E.J.; Chen, W. MEMS resonators for frequency reference and timing applications. J. Microelectromech. Syst. 2020, 29, 1137-1166. [CrossRef]

10. Wu, G.; Xu, J.; Zhang, X.; Wang, N.; Yan, D.; Lim, J.L.K.; Zhu, Y.; Li, W.; Gu, Y. Wafer-level vacuum-packaged high-performance AlN-on-SOI piezoelectric resonator for Sub-100-MHz oscillator applications. IEEE Trans. Ind. Electron. 2017, 65, 3576-3584. [CrossRef]

11. Powell, D.A.; Kalantar-zadeh, K.; Wlodarski, W. Numerical calculation of SAW sensitivity: Application to $\mathrm{ZnO} / \mathrm{LiTaO}_{3}$ transducers. Sens. Actuators A Phys. 2004, 115, 456-461. [CrossRef]

12. Didenko, I.S.; Hickernell, F.S.; Naumenko, N.F. The experimental and theoretical characterization of the SAW propagation properties for zinc oxide films on silicon carbide. IEEE Trans. Ultrason. Ferroelectr. Freq. Control 2000, 47, 179-187. [CrossRef] [PubMed]

13. Hartmann, C.S. A fast accurate method for calculating the SAW and bulk wave radiation admittance of a SAW transducer. IEEE Ultrason. Symp. 1988, 39-46. [CrossRef]

14. Peng, D.; Yu, F. A novel FEA simulation model for RFID SAW tag. IEEE Trans. Ultrason. Ferroelectr. Freq. Control 2009, 56, 1753-1760. [CrossRef] [PubMed]

15. Koskela, J.; Maniadis, P.; Willemsen, B.A.; Turner, P.J.; Hammond, R.B.; Fenzi, N.O.; Plessky, V. Hierarchical cascading in 2D FEM simulation of finite SAW devices with periodic block structure. IEEE Int. Ultrason. Symp. (IUS) 2016, 1-4. [CrossRef]

16. Kaletta, U.C.; Wipf, C.; Fraschke, M.; Wolansky, D.; Schubert, M.A.; Schroeder, T.; Wenger, C. AlN $/ \mathrm{SiO}_{2} / \mathrm{Si}_{3} \mathrm{~N}_{4} / \mathrm{Si}(100)-$ based CMOS compatible surface acoustic wave filter with $12.8 \mathrm{~dB}$ minimum insertion loss. IEEE Trans. Electron Devices 2015, 62, 764-768. [CrossRef]

17. Manner, O.; Machui, J.; Ali-Hackl, M.; Ruile, W. 2D simulation of diffraction and reflection improves Z-path SAW filters for mobile communications. Proc. IEEE Ultrason. Symp. 1995, 1, 277-280. [CrossRef]

18. Qamar, A.; Jafari, M.; Rais-Zadeh, M. Solidly mounted anti-symmetric Lamb-wave delay lines as an alternate to SAW devices IEEE Electron Device Lett. 2018, 39, 1916-1919. [CrossRef]

19. Oh, H.; Lee, K.; Eun, K.; Choa, S.; Yang, S.S. Development of a high-sensitivity strain measurement system based on a SH SAW sensor. J. Micromech. Microeng. 2012, 22, 025002. [CrossRef]

20. Jia, L.; Shi, L.; Liu, C.; Sun, C.; Wu, G. Enhancement of transmitting sensitivity of piezoelectric micromachined ultrasonic transducers by electrode design. IEEE Trans. Ultrason. Ferroelectr. Freq. Control 2021. [CrossRef]

21. Jia, L.; Shi, L.; Liu, C.; Yao, Y.; Sun, C.; Wu, G. Design and characterization of an aluminum nitride-Based MEMS hydrophone with biologically honeycomb architecture. IEEE Trans. Electron Devices 2021, 68, 4656-4663. [CrossRef]

22. Chen, Q.; Wang, Q.M. The effective electromechanical coupling coefficient of piezoelectric thin-film resonators. Appl. Phys. Lett. 2005, 86, 022904. [CrossRef] 